\title{
Materiais manipuláveis para aprender e ensinar geometria
}

\section{Isabel Vale}

Professora, Escola Superior de Educação do Instituto Politécnico de Viana do Castelo isabel.vale@ese.ipvc.pt

\author{
Ana Barbosa \\ Professora, Escola Superior de Educação do Instituto Politécnico de Viana do Castelo \\ anabarbosa@ese.ipvc.pt
}

\begin{abstract}
Resumo
A utilização de materiais manipuláveis é sugerida por vários autores como sendo uma mais valia na construção de conceitos matemáticos. Assim o desenvolvimento do pensamento geométrico dos estudantes pode ser mais facilmente conseguido através de tarefas desafiantes que recorram a materiais manipuláveis diversificados. Deste modo é crucial que os (futuros) professores desenvolvam as aptidões necessárias para utilizar materiais na sala de aula, numa perspectiva de ensino e aprendizagem mais dinâmica e desafiadora. Pretende-se neste artigo relatar algumas experiências de sala de aula, baseadas em tarefas geométricas exploradas com recurso a materiais manipuláveis, onde é dada grande ênfase à resolução de problemas e à experimentação, realizadas durante um estudo com futuros professores do ensino básico (3-12 anos). Os resultados mostram que os futuros professores envolveram-se nas tarefas propostas e construíram conhecimento geométrico em relação aos conteúdos abordados através dos materiais manipuláveis.
\end{abstract}

Palavras-chave: Materiais Manipuláveis. Geometria. Futuros Professores. Educação Básica.

\section{Manipulative materials to learn and teach geometry}

\begin{abstract}
The use of manipulative materials is suggested by several authors as an asset in the development of mathematical concepts. Thus the development of students' geometric thinking can be easily achieved through challenging tasks that make use of diverse manipulative materials. It is crucial that (future) teachers develop the skills needed to use manipulative in the classroom with a more dynamic and challenging perspective of teaching and learning. In this paper we intend to report some classroom experiences, conducted with future teachers from basic education (3-12 years), based on geometry tasks explored, with manipulative materials, when problem solving and experimentation are privileged. Result show that the future teachers were involved in the proposed tasks and constructed geometric knowledge related to the approached contents through the manipulative materials.
\end{abstract}

Keywords: Manipulative Materials. Geometry. Future teachers. Elementary Education. 


\section{A geometria e os materiais manipuláveis}

A Geometria tem sido tradicionalmente um tema negligenciado na matemática escolar, principalmente nos níveis mais elementares, apesar dos muitos benefícios que pode proporcionar aos estudantes, mesmo quando apresentada de forma intuitiva e informal. As experiências em geometria com que normalmente são confrontados limitam-se aos níveis mais baixos de raciocínio,

sendo bastante reduzidas as experiências significativas que podem contribuir para o desenvolvimento de capacidades de raciocínio mais elevadas. Mesmo os estudantes de níveis de escolaridade avançados, apesar de já possuírem maior capacidade de abstração, também raramente são confrontados com tarefas significativas e desafiantes em geometria, continuando a ser privilegiadas tarefas rotineiras (VALE; PIMENTEL, 2012).

Pode-se afirmar que a geometria é um tema matemático no qual os estudantes apresentam dificuldades, e onde evidenciam fracos resultados, quer em provas nacionais quer internacionais, o que faz com que a comunidade de educadores matemáticos deve dar uma atenção especial a este tema. Os estudantes devem ser motivados para a aprendizagem da geometria, para isso deve serlhes mostrada a sua importância como parte do mundo que nos rodeia, compreendendo simultaneamente as relações entre o mundo concreto e abstrato da geometria.

É amplamente reconhecida a importância do papel que o pensamento geométrico tem na matemática, por isso, é necessário reforçar o ensino e a aprendizagem com processos que permitam aos alunos desenvolver a sua intuição e percepção espacial (JONES, 2001). Em particular, a visualização tem um papel importante como componente do raciocínio matemático (e.g. DREYFUS, 1990; JONES, 2001; PRESMEG, 2006; van HIELE, 1999) com fortes ligações à geometria. Assim, a aprendizagem matemática deve incluir práticas que conduzam os alunos a pensar visualmente e a desenvolver essa capacidade através de experiências que requeiram tal forma de pensamento. Um meio pode ser através do recurso a materiais manipuláveis e às diferentes representações que a partir daí podem emergir e se podem utilizar (PIMENTEL; VALE, 2013).

Os educadores matemáticos há bastante tempo que se têm interessado pela utilização de materiais concretos de natureza diversa, como suporte da aula de matemática, a fím de contextualizar alguns conceitos matemáticos mais abstratos e, portanto, facilitar a sua compreensão. Do ponto de vista construtivista os alunos parecem aprender matemática de uma forma mais eficiente quando recorrem aos materiais manipuláveis que naturalmente lhes permitem construir novos conhecimentos e, assim, envolver-se na sua própria aprendizagem. De acordo com van Hiele (1999), o ensino da geometria deve incluir, em todos os níveis, a utilização de materiais que os alunos possam manipular pois, só assim, adquirem uma compreensão das propriedades geométricas e das suas relações. A investigação também mostra que o uso de materiais manipuláveis (e.g. 
geoplanos, papel, modelos de formas geométricas em madeira ou plástico, sólidos, miras, espelhos, policubos) pode ser útil no desenvolvimento de representações geométricas, mas devem ser utilizados sabiamente (CLEMENTS, 2004). É neste sentido que vários educadores e entidades educativas recomendam a sua utilização (e.g. CLEMENTS, 1999; CLEMENTS 2004; MATOS; SERRAZINA, 1996; REYS; LINDQUIST; LAMBDIN; SMITH, 2006; SZENDREI, 1996; WEISS, 2006).

Dois estudos recentes, de natureza qualitativa, realizados por Pinheiro (2013) e Pita (2014) no âmbito do ensino das transformações geométricas, em particular das isometrias, com alunos do $6^{\circ}$ ano de escolaridade (10-12 anos), chegaram a resultados muito semelhantes em relação à utilização de materiais manipuláveis. Pinheiro (2013) concluiu que os materiais manipuláveis, quando acompanhados de tarefas desafiantes e com tempo suficiente para os alunos fazerem explorações, contribuem para a compreensão das isometrias, para além de potenciarem o desenvolvimento da comunicação, da argumentação e do raciocínio matemático. O estudo refere ainda que os materiais manipuláveis podem ser facilitadores da representação e descrição de conceitos matemáticos e que a sua manipulação e exploração dão oportunidade aos alunos de se apropriarem de um conjunto de propriedades geométricas. Pita (2014) concluiu que a realização de tarefas sobre isometrias, com recurso a materiais manipuláveis, contribuiu significativamente para a aprendizagem de conceitos geométricos, através das experiências individuais de cada aluno, e facilitou as interações entre os alunos, originando momentos de partilha de idéias e discussão de raciocínios e procedimentos.

Contudo, existem ainda poucas evidências de que os professores utilizem materiais manipuláveis de forma efetiva, contextualizada e continuada com os seus alunos nas aulas de matemática. Há três razões que podem fundamentar este facto: uma visão tradicional de ensino da matemática e de aprendizagem, que ainda se verifica nas aulas desta disciplina, onde o foco é a memorização e a prática, na qual o professor explica o assunto, principalmente através de procedimentos, regras e algoritmos e os alunos reproduzem o que observam, fazendo exercícios repetitivos; os professores poderão não conhecer os materiais manipuláveis ou estar familiarizados com a sua utilização de modo eficaz, atendendo aos diversos temas do currículo de matemática e ao nível dos estudantes; o tempo que este tipo de abordagem necessita, assim como a dinâmica de sala de aula que proporciona, e que os professores, por razões de natureza curricular e/ou pedagógica, preferem não utilizar.

Assim, as instituições de formação têm um papel importante a desempenhar na formação de professores, quer inicial quer continuada, que deve estar de acordo com as mais recentes 
recomendações da investigação, em particular, sobre a utilização destes poderosos recursos que são os materiais manipuláveis.

\section{Os materiais manipuláveis e a formação de professores}

Desde os tempos mais remotos que o recurso a materiais concretos no ensino e aprendizagem matemática tem sido uma constante. Por exemplo, para contar animais o homem primitivo pastor começou a usar pedras ou marcas numa vara. Mais tarde, com a introdução do sistema de numeração indo-árabe, surgiu o ábaco. Este foi um dos primeiros materiais construídos especificamente para trabalhar conceitos de aritmética, tendo o eclesiástico Gerbert (930-1003) aprofundado as suas aplicações. No entanto, no séc. XV este tipo de material desapareceu das escolas, especialmente quando apareceram novos métodos de cálculo - os poderosos algoritmos. Os materiais manipuláveis foram reintroduzidos e recomendados mais tarde pelos defensores da Escola Ativa, Comenius e Pestalozzi, que, apesar de serem de épocas diferentes e com visões diferenciadas, defenderam os mesmos princípios. Mais tarde, vários educadores (e.g. Bruner, Castelnuovo, Cuisenaire, Decroly, Dienes, Gattegno, Montessori, Piaget) introduziram novas perspectivas e abordagens em relação ao ensino e aprendizagem da matemática, assim como novos materiais didáticos (VALE, 2002).

Partindo da idéia de que um material didático é todo aquele a que recorremos para promover o ensino e aprendizagem, neste caso, da matemática, considera-se um material manipulável todo o material concreto, educacional ou do dia a dia (e.g. ábaco, policubos, folhas de papel, bolas de gude), que represente uma idéia matemática, que durante uma situação de aprendizagem apele aos sentidos e que se caracteriza por um envolvimento ativo dos alunos. Por exemplo, o geoplano é um material educativo pois foi desenvolvido numa perspectiva educacional, enquanto uma folha de papel ou um conjunto de bolas de gude são materiais de uso comum que não foram desenvolvidos com uma finalidade educativa, mas que podem ser usados com esse propósito.

Para aprender matemática é necessário ação, real e/ou virtual, reflexão e competência de ser capaz de relacionar ambas. A matemática começa, na maioria das vezes, com uma ação sobre os objetos, mas pode não ficar por aí. Um material manipulável não contém ou produz matemática, apenas cada pessoa pode fazê-lo com a sua mente. É necessário reforçar que os conceitos matemáticos são abstratos, assim qualquer modelo que englobe esses conceitos tem limitações: o modelo apenas proporciona o contexto favorável para a compreensão dos conceitos matemáticos que estão a ser tratados.

Quando um professor proporciona aos alunos oportunidades de um ensino que utilize materiais manipuláveis, embora estes benefícios possam ser tênues, as atitudes dos alunos face à 
matemática melhoram e, de modo geral, a compreensão dos conceitos matemáticos aumenta. Há autores (e.g. KELLY, 2006) que defendem a utilização de materiais manipuláveis por considerarem que, através da experimentação com diferentes materiais, os alunos têm oportunidade de verificar intuitivamente como é que as coisas funcionam, o que contribui para a fluência e flexibilidade no raciocínio. Sobretudo os estudantes mais jovens precisam que lhes sejam dadas várias oportunidades para trabalhar os conceitos do mundo físico antes de trabalharem com imagens e outras representações. Somente após esse trabalho estarão prontos para trabalhar no mundo abstrato dos símbolos (WEISS, 2006).

As capacidades dos professores para utilizarem uma abordagem didática com materiais manipuláveis são fundamentais para o sucesso de uma nova visão do ensino e aprendizagem da matemática. Isso implica repensar as aulas, as disciplinas de didática e as práticas de ensino nos currículos de formação de professores. A investigação deve estar assim direcionada para proporcionar os conhecimentos necessários aos professores que lhes permitam colocar em prática essas recomendações. Numa perspectiva construtiva e intuitiva da geometria um desenho ou uma idéia podem ser insuficientes para a compreensão de um conceito geométrico por parte de alguns alunos, tendo por isso necessidade de recorrer ao concreto. Não é o material em si que é importante, mas as transformações realizadas sobre ele. É através de uma série contínua de tentativas efetuadas sobre o material, o que não é possível por exemplo apenas com um desenho, que os alunos descobrem relações e propriedades, facilitando o salto do concreto para o abstrato. Os professores devem ajudar os estudantes a compreender as relações que se estabelecem entre o modelo (contexto) e a matemática, o que é um grande desafio, mas é também uma experiência gratificante para o professor.

$\mathrm{O}$ ambiente de aprendizagem nas aulas de didática, das quais se relatam aqui alguns exemplos, seguem uma abordagem exploratória, em que as principais idéias matemáticas surgem das tarefas, com recurso a materiais manipuláveis, que os alunos resolvem e das discussões produzidas sobre as estratégias utilizadas, direcionadas para os conceitos envolvidos e os aspetos didáticos mais relevantes relacionados com a tarefa. Na nossa opinião, há vantagens para os professores quando lhes são dadas oportunidades para explorar uma variedade de estratégias de ensino e recursos didáticos durante a sua formação inicial.

Por outro lado, deve ser proporcionado aos futuros professores um ambiente de aprendizagem o mais alinhado possível com aquele que se pretende que venham a desenvolver com os seus respectivos alunos. Deste modo, precisam de ter os conhecimentos necessários sobre o potencial dos materiais manipuláveis, mas também das suas fragilidades e limitações, e ter a capacidade de identificar quais os que mais se adéquam a um determinado tema e desenvolver tarefas 
matematicamente ricas e desafiantes para a sua utilização, de acordo com os objetivos pretendidos. É assim essencial que os programas de formação de professores inicial e continuada abordem esta temática com situações concretas de sala de aula pois só se pode ensinar com sucesso se se dominar aquilo que se ensina em particular quando se trata da utilização de materiais manipuláveis.

\section{O contexto e a experiência didática}

Nas disciplinas de didática da matemática que lecionamos num curso de Licenciatura em Educação Básica, numa instituição de formação inicial de professores, que prepara professores para o ensino básico (3-12 anos) é dada grande ênfase à resolução de problemas e à experimentação com recurso a materiais manipuláveis, privilegiando-se o questionamento entre professor e aluno(s). Apesar de utilizarmos vários materiais estruturados, privilegiamos os mais simples, de uso comum, sobretudo aqueles que podem ser construídos pelos alunos, por duas razões: uma prende-se com o fator econômico e com a acessibilidade; e a outra, a principal, é que os alunos quando constroem o seu próprio material envolvem-se nessa construção, acabando por ser também um processo de aprendizagem e uma forma de ganharem laços afetivos com o material, com todas as vantagens que daí advêm.

Deste modo, desenvolvemos um estudo com o objetivo de compreender o desempenho de futuros professores em tarefas que recorram à utilização de materiais manipuláveis que envolvem conceitos no âmbito da geometria. A folha de papel é o material manipulável privilegiado nas tarefas aqui apresentadas - o mais simples, mais econômico e acessível em qualquer aula. Os episódios apresentados resultam de algumas das tarefas utilizadas durante a proposta didática realizada nas aulas de duas turmas de cerca de 25 alunos cada, cerca de 9 horas, durante o módulo de geometria, onde os alunos trabalharam em pares. Assumimos uma perspectiva interpretativa na recolha e análise de dados que foi concretizada pela observação participante das aulas e pelas produções dos alunos, no contexto natural de sala de aula (e.g. DENZIN; LINCOLN, 2000).

As situações propostas pretendem ser desafiantes e ricas, no sentido de atraírem o aluno para a sua resolução, suscitando a sua curiosidade, imaginação e criatividade, quer por permitir introduzir ou aplicar idéias matemáticas fundamentais, proporcionando múltiplas abordagens de resolução - representações, conteúdos e processos que podem ser utilizados.

São explorados diversos materiais durante as aulas que lhes permitam vivenciar o maior número de situações através de tarefas adequadas, refletindo sobre a tarefa e sobre o(s) material(ais), sempre do modo mais próximo daquele que se espera que venham a utilizar nas suas próprias aulas, inventariando as possíveis abordagens, questões e dificuldades que possam surgir numa aula. 


\section{Alguns flashes da experiência didática}

As tarefas a seguir apresentadas podem ser utilizadas diretamente com alunos do Ensino Básico, $1^{\circ}$ ciclo (6-10 anos) e $2^{\circ}$ ciclo (10-12 anos), ou com pequenos adaptações.

Tarefa 1. Determinar a expressão que nos permite calcular a área do círculo a partir de um círculo de papel.

Esta tarefa tinha como objetivo determinar a expressão que permite calcular da área do círculo, a partir de um círculo de papel. Para isso, os alunos foram desafiados a partir de um círculo de papel, descobrir uma figura de área equivalente da qual já soubessem calcular a área. Foram então distribuídos pelos alunos três círculos de papel iguais e uma tesoura.

A aula desenrolou-se com os alunos a fazerem experiências várias com o círculo recorrendo a dobragens e a recortes. O círculo foi sendo dividido em setores e os alunos foram efetuando as suas experiências e conjeturas, sendo o trabalho orientado à medida que houvesse solicitações. A primeira tentativa foi dividir o círculo em quartos. Tentaram construir uma figura com as 4 peças mas não conseguiram identificar nenhuma forma conhecida.
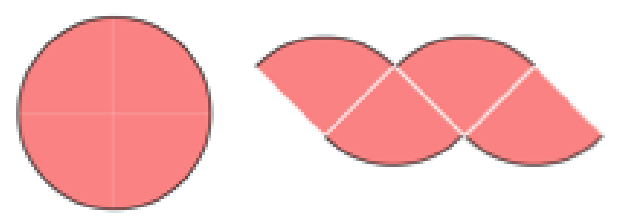
Alguém se lembrou de cortar em oitavos. E a partir daqui começaram a aperceber-se que as figuras "quase" formavam um paralelogramo, e rapidamente "viram" que cortar o círculo em setores mais pequenos iria ajudar a encontrar o que pretendiam.
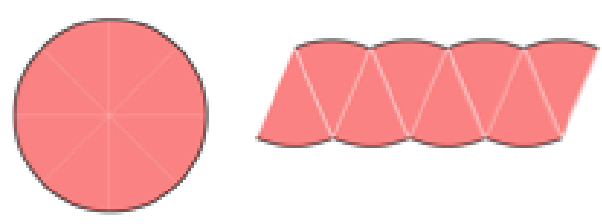

Experimentaram dividi-lo em dezesseis partes. Na Figura 1 estão ilustradas as diferentes fases até à transformação do círculo num paralelogramo. Entretanto questionou-se se não haveria a possibilidade de transformar o paralelogramo num retângulo. Rapidamente uma aluna dividiu um dos setores em duas partes congruentes e colocou-os nos lados opostos da última figura, obtendo uma forma muito próxima do retângulo (Fig.2).

A partir desta figura, e comparando-a com o círculo inicial, conseguiram chegar às dimensões do retângulo e $R$ conseqüentemente à sua área $\pi \mathrm{R}^{2}$. Deste modo, como o círculo $\mathrm{e}$ o retângulo são equivalentes, o que facilmente se comprovou, pois foi utilizado o mesmo papel, concluíram que a área do

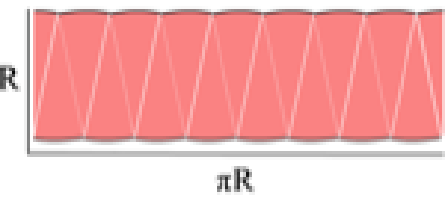

Fig.2 circulo é $\pi \mathrm{R}^{2}$. 
Estes alunos sabiam a fórmula da área do círculo e tinham adquirido o conhecimento formal de como obter a expressão para determinar a sua área, utilizando um processo conceitualmente mais exigente e abstrato. Quando confrontados com a questão de que a área do círculo faz parte do programa de matemática do ensino básico, interrogaram-se sobre como o fazer de modo a que as crianças entendessem sem ter que recorrer a conhecimentos matemáticos complexos que não tinham. Depois desta experiência, com recurso a material simples (papel e tesoura) e na discussão conjunta no final da tarefa, reconheceram que este processo permite obter a fórmula da área do círculo de um modo mais intuitivo e interessante, sem ter que recorrer a estratégias complexas ou à memorização, apelando à utilização de conhecimento matemático com significado e mais duradouro.

Tarefa 2. Durante as férias de Natal a Ana e as suas colegas tiveram que arranjar cinco grandes mesas quadradas iguais para o jantar da noite de Natal. Desenha todos os diferentes modos em que podem ser colocadas as

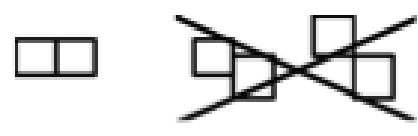

Fig.3 mesas para a festa, de forma a que cada mesa tenha pelo menos um lado em comum (Fig.3).

Esta tarefa tinha como objetivo obter os diferentes pentaminós, partindo de um problema com mesas. Antes de iniciarem a resolução do problema foi discutido com a turma a condição a que tinha de obedecer a disposição das mesas, tendo sido usados dois contraexemplos (Fig.3).

Para resolver este problema recortaram pequenos quadrados em papel que foram justapondo de modo a obter o máximo de hipóteses. Depois registraram as suas descobertas. Encontraram muitos modos de dispor os quadrados mas eis que surgem os quatro modos apresentados na Figura 4. Foi aberta a discussão na turma sobre se deveriam considerar estas representações como sendo diferentes ou equivalentes. Os alunos concluíram que seriam

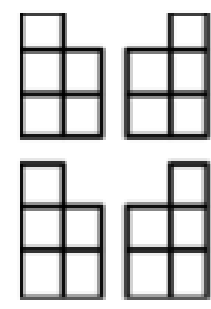

Fig.4 apenas um modo, pois foram obtidas efetuando algumas transformações geométricas numa dessas figuras (rotações e/ou reflexões). Depois de mais tentativas descobriram que a Ana e as colegas tinham 12 modos diferentes de dispor as mesas (Fig.5).

A questão aqui era saber que garantias tinham de que estas soluções representavam todos os modos possíveis e se não havia alguma repetida. Chegaram à conclusão que não tinham certezas,

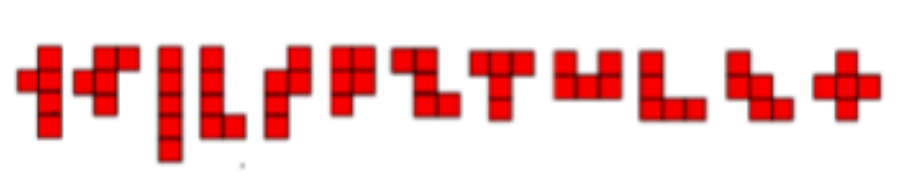

Fig.5 pois a estratégia utilizada, tentativa e erro, não lhes permitia verificar. Sugeriu-se que olhassem de novo para as formas obtidas e tentassem descobrir um modo que lhes 
desse essa garantia. Sugestão que foi acatada, tendo os alunos recorrido a uma lista organizada. Por exaustão, conseguiram determinar todos os modos de obter as 12 figuras. O critério escolhido foi começar por dispor 5 quadradinhos em linha; depois $4 \mathrm{em}$ linha e fazer variar a posição do $5^{\circ}$ quadrado; 3 em linha e fazer variar o $4^{\circ}$ e $5^{\circ}$ quadrados; e por fim 2 em linha. Por exaustão e organização dos dados estavam encontradas todas as hipóteses pedidas (Fig.6).

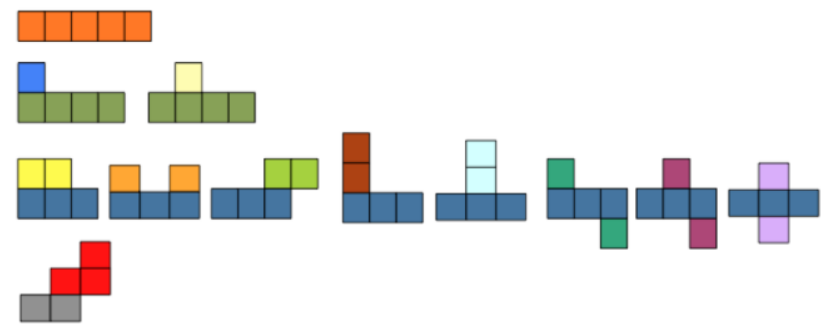

Fig.6

Finalmente, foram informados de que as figuras obtidas, constituídas por cinco quadrados iguais, chamavam-se pentaminós e que cada uma delas usualmente é designada por uma letra do alfabeto que mais se assemelhe à sua forma. A partir daqui propuseram-se várias tarefas a partir dos pentaminós (e.g. descobrir quais tinham eixo(s) de simetria de reflexão; quais permitiam construir uma caixa aberta; qual/quais o(s) que tinha(m) maior perímetro). A discussão sobre esta tarefa mostrou que ficaram sobretudo interessados no modo de introduzir este material (pentaminós) através da resolução de um problema que aparentemente nada tinha a ver com o material. Depois de provarem que apenas há 12 peças que constituem os pentaminós, essencial para os alunos compreenderem a necessidade de haver processos que permitem dar-nos garantia de que estamos corretos, formularam novos problemas com base nos pentaminós.

\section{Tarefa 3. Construir frisos utilizando dobragens e recortes.}

Esta tarefa tinha por objetivo que os alunos construíssem alguns frisos que lhes foram apresentados recorrendo a dobragens e recortes de papel e que envolviam conceitos do âmbito das transformações geométricas. Este tipo de tarefas nunca tinha sido até então explorada por estes alunos do ponto de vista matemático.

Os alunos estão por norma familiarizados com a dobragem de papel para construir figuras simples com um eixo de simetria, e partindo desta idéia, iniciou-se a tarefa com uma folha de papel que os alunos tinham que dobrar e recortar de modo a obter o friso da Figura 7, que não é mais do que um padrão de repetição do tipo AAA (friso que para além da translação tem simetria de reflexão de eixo vertical).

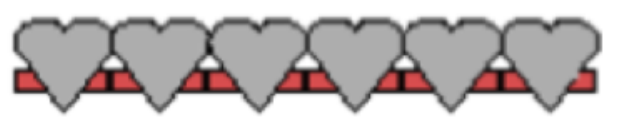

Fig.7

Esta tarefa parecia não causar qualquer dificuldade, no entanto a maioria dos alunos obteve figuras soltas, um coração e não um friso de corações. Rapidamente, em discussão uns com os 
outros, e em questionamento com o docente, conseguiram identificar o erro cometido, isto é, não poderiam recortar completamente as figuras. Todos conseguiram chegar a essa conclusão.

Apresentou-se de seguida uma nova imagem (Fig.8) de um novo friso para obterem por dobragens e recortes, envolvendo um padrão do mesmo tipo que o anterior.

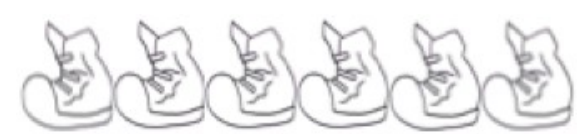

Fig.8 Este exemplo foi muito interessante. Depois de várias tentativas e de obterem, por exemplo, frisos

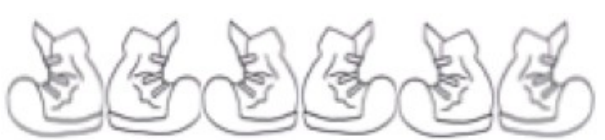

Fig.9 do tipo da Fig.9, houve grande discussão, levando a que se analisasse o friso anterior para ver qual a propriedade que o friso não tinha que não permitia obtê-lo por dobragens. Conseguiram descobrir que o exemplo dado era impossível de obter, pois só seria possível se a figura simples que compõe o friso (a bota) tivesse uma simetria de reflexão, ou seja um eixo de simetria, o que não acontece.

A outra tarefa de dobragens proposta consistiu em dobrar e recortar o papel de modo que ao desdobrar obtivessem um padrão de repetição do tipo ABABAB (Fig.10). Ou seja o friso é obtido pela translação do motivo composto por uma

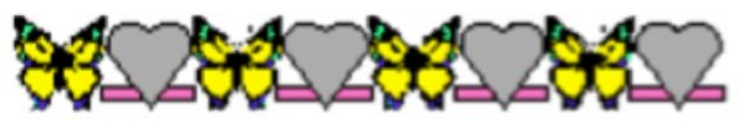

Fig.10 borboleta e um coração. Nesta tarefa as dificuldades foram maiores. Começaram por fazer várias tentativas a dobrar e a cortar obtendo outras figuras, mais uma vez separadas. Depois de alguma discussão e de refletirem sobre as propriedades de uma figura e em que condições é que tem simetria de reflexão, uma aluna descobriu como dobrar o papel explicando à turma como pensou: "têm que desenhar metade de cada uma das figuras que Fig.11 compõem o friso" (Fig.11).

Esta tarefa foi muito proveitosa para estes futuros professores. Os frisos de papel são muito utilizados nas alturas festivas nas escolas pelo seu aspeto visual, com esta tarefa ficaram alertados de que poderão também trabalhar matemática e de um modo cativante para os alunos.

Tarefa 4. Dobra-se uma folha ao meio. Quantas regiões se obtém? Qual a área de cada região ao fim de n dobragens?

Esta tarefa tinha por objetivo identificar as estratégias a que os alunos recorrem para resolver o problema. Pretendia-se que identificassem os conteúdos que a tarefa envolve, mobiliza ou pode mobilizar, para além do que é expresso no enunciado.

Este tipo de problemas tende a deixar os alunos desorientados, sem saberem por onde começar, mas o trabalho que se tem vindo a desenvolver com a generalização de sequências com padrões de crescimento tem tido um impacto positivo. Assim, ao iniciar a resolução do problema, os alunos recorreram a uma folha de papel para efetuar as dobragens. Começaram então a dobrar a 
folha, mas verificaram que não iam além das quatro dobragens, pois o papel era grosso. Então mudaram de estratégia e decidiram fazer alguns desenhos. Em seguida, recorrendo a uma tabela e reduzindo o problema a um outro mais simples, rapidamente chegaram ao padrão e à resposta. A Figura 12 resume os passos seguidos na resolução deste problema.

\begin{tabular}{|c|c|c|}
\hline $\mathrm{N}^{\circ}$ de dobragens & $\mathrm{N}^{\circ}$ de regiões & $\begin{array}{c}\text { med. da área de } \\
\text { cada região }\end{array}$ \\
\hline 0 & $1=2^{0}$ & $1=1 / 2^{0}$ \\
\hline 1 & $2=2^{1}$ & $1 / 2=1 / 2^{1}$ \\
\hline 2 & $4=2^{2}$ & $1 / 4=1 / 2^{2}$ \\
\hline 3 & $8=2^{3}$ & $1 / 8=1 / 2^{3}$ \\
\hline$\ldots$ & $\ldots$ & $\ldots$ \\
\hline 10 & $2^{10}$ & $1 / 2^{10}$ \\
\hline$\ldots$ & $\ldots$ & $\ldots$ \\
\hline $\mathrm{n}$ & $2^{\mathrm{n}}$ & $1 / 2^{\mathrm{n}}$ \\
\hline
\end{tabular}

Fig.12

A parte mais interessante da exploração desta tarefa foi a discussão que se seguiu sobre os conteúdos abordados, os níveis de ensino em que poderia ser utilizada e se seria, ou não, uma tarefa a desenvolver com alunos do $2 .^{\circ}$ ciclo (10-12 anos) e em que moldes. Nesse sentido, foi referido que esta tarefa poderia promover o recurso a várias representações (concreta, pictórica, gráfica) e poderia ser explorada até ao ensino secundário com recurso à calculadora como aplicação da função exponencial. Os alunos evidenciaram satisfação ao constatar que uma proposta de trabalho tão simples e interessante poderia aglomerar tantas idéias matemáticas. Foi-lhes referido que esta é uma das finalidades da matemática, que os alunos consigam matematizar situações desta natureza. Trata-se de uma tarefa bastante rica pois permite abordar vários conteúdos: números racionais sob a forma de frações (parte-todo e operador); operações com frações; potências; área; generalização; pensamento recursivo e funcional; noção intuitiva de limite, .... estas conclusões nasceram da discussão final. Depois houve uma seleção dos conteúdos que poderiam ser tratados para os níveis que irão lecionar. O que mais gostaram nesta tarefa foi recorrer apenas a uma folha de papel e envolver tantos conteúdos, sobretudo a relação parte todo e a área. Contudo, concordaram que esta tarefa, para ser utilizada com os seus futuros alunos, teria de ser ligeiramente alterada para melhor compreensão, sendo essencial recorrer ao material, a folha. A proposta a que se chegou depois da discussão geral foi a que se segue. De notar o pormenor de utilizarem uma folha de papel de seda para dar oportunidade aos alunos, que tenham mais dificuldade de generalizar, de dobrar o papel mais vezes, pois é mais fino: 
Material: Uma folha de papel seda.

Desenvolvimento: Dobra a folha de papel ao meio. Com esta primeira dobragem

obténs duas regiões.

1. Quantas regiões obténs ao fim de três dobragens? E ao fim de quatro?

2. Quantas dobragens consegues efetuar? Se conseguisses efetuar 10 dobragens

quantas regiões obterias?

3. Qual é a área de cada uma das regiões obtidas?

4. Consegues prever quantas partes obterias se dobrasses a folha 20 vezes? Explica

como pensaste.

\section{Algumas reflexões}

Os materiais manipuláveis podem ajudar na construção de conceitos e na resolução de problemas de matemática, devem ser usados quando forem necessários, independentemente da idade dos alunos, e têm potencialidades e fragilidades que os professores devem saber identificar. Embora a investigação apóie esta idéia nem todos os temas, nem todos os alunos beneficiam do recurso a materiais manipuláveis.

Das observações realizadas constatou-se que houve uma participação entusiástica por parte dos alunos e há significativas vantagens na utilização dos materiais, não só na aquisição de conceitos matemáticos, muitos deles revisitados, mas nalguns casos só nesta altura compreendidos, mas também numa perspectiva futura como professores ao aperceberem-se do seu potencial educativo e da forma como poderão ser explorados.

Ao longo da resolução destas tarefas, onde se recorreu a uma folha de papel, os alunos ficaram surpreendidos com a forma como a manipulação de um material tão simples pode ajudar a explorar e explicar tantos conceitos matemáticos e a resolver problemas de natureza tão diferente, desafiando a sua compreensão, através de estratégias que os podem ajudar no ensino e aprendizagem de conceitos matemáticos com os seus futuros alunos e a melhorarem a sua própria compreensão de conceitos fundamentais. Por outro lado, os futuros professores também constataram que, num contexto laboratorial deste tipo, o papel do professor é mais complexo e exigente do que no tradicional (e.g. SZENDREI, 1996)

Durante as aulas alguns alunos disseram "... Como eu gostaria que me tivessem ensinado como estou a aprender para a ensinar agora ... ". Esta frase revela que estes estudantes tomaram consciência de um modo de ensinar e aprender matemática, através de múltiplas representações, que gostariam de ter tido experimentado enquanto alunos do mesmo nível daquele para o qual estão a ser preparados. Adquiriram uma visão mais positiva da matemática e tornaram-se mais atentos e conscientes das suas próprias capacidades e conhecimentos.

Esta abordagem didática, realizada ao nível da formação de professores, com recurso a materiais manipuláveis, em que são dadas oportunidades de experimentar, observar, conjeturar, provar, colaborar, proporcionou a aquisição de poderosos insights sobre o ensino e sobre a aprendizagem da geometria contribuindo para o seu conhecimento matemático e didático (e.g. 


\section{Referências}

CLEMENTS, D. Concrete manipulatives, concrete ideas. Contemporary issues in early childhood, v. 1, p. 45-60. 1999.

CLEMENTS, L. A model for understanding, using and connecting representations. Teaching children mathematics, v. 11, p. 97-101. 2004.

DENZIN, N.; LINCOLN, Y. Handbook of qualitative research. Newbury Park: Sage, 2000.

DREYFUS, T. Advanced mathematical thinking. mathematics and cognition: a research synthesis by the international group for the psychology of mathematics education. Cambridge: Cambridge University Press, 1990.

JONES, K. Spatial thinking and visualization. Teaching and learning geometry, p. 11-19. London, UK: Royal Society. 2001.

KELLY, C. Using manipulatives in mathematical problem solving: A performance-based analysis. university of colorado at colorado springs. The montana mathematics enthusiast, v. 3, n. 2, p. 184-193. 2006.

MATOS, J.M.; SERRAZINA, L. Didáctica da Matemática. Lisboa: Universidade Aberta, 1996.

PIMENTEL, T.; VALE, I. Reasoning in geometry: the role of the tasks. In: B. DI PAOLA (Ed.), Proceedings of CIEAEM 65 - Comission interantionale pour l'étude et l'ámélioration de l'énseignement des mathemátiques. - Mathematics in a globalized environment. Torino, Italy: Universitá de Torino, 2013. p. 147-156.

PINHEIRO, C. Os materiais manipuláveis e a geometria num contexto das isometrias - um estudo no $6^{\circ}$ ano de escolaridade no ensino básico. Dissertação de mestrado. Viana do Castelo: Escola Superior de Educação, 2013.

PITA, C. As Transformações geométricas e os materiais manipuláveis: um estudo no $6^{\circ}$ ano de escolaridade. Relatório de prática de ensino supervisionada. Viana do Castelo: Escola Superior de Educação, 2014.

PRESMEG, N. C. Research on visualization in learning and teaching mathematics: Emergence from psychology. In: A. GUTIERREZ \& P. BOERO (Eds.), Handbook of research on the psychology of mathematics education, Rotterdam: Sense Publishers. 2006. p. 205-235.

REYS, R.; LINDQUIST, M.; LAMBDIN, D.; SMITH, N. Helping children learn mathematics. Kendaville: Wiley, 2006.

SZENDREI, J. Concrete materials in the classroom. In: A. BISHOP, K. CLEMENTS, C. KEITEL, J. KILPATRICK, C. LABORDE (Eds.), International handbook of mathematics education, Dordrecht: Kluwer Academic Publishers, 1996. p. 411- 434.

VALE, I. Materiais manipuláveis. Viana do Castelo: ESEVC-LEM, 2002. Disponível em https://ipvc.academia.edu/Isabe lVale. Acesso em 10 de nov. de 2013

VALE, I.; PIMENTEL, T. A utilização da visualização para ensinar a aprender matemática. In: H. PINTO, H. JACINTO, A. HENRIQUES, A. SILVESTRE, C. NUNES (Orgs.), Atas do XXIII SIEM - Seminário de investigação em educação matemática, Lisboa: APM, 2012. p. 245-257. VAN HIELE, P. Developing geometric thinking through activities that begin with play. Teaching children mathematics, v. 6, p. 310-316. 1999. 
WEISS, D. The rationale for using manipulatives in the middle grades. Mathematics teaching in the middle school, v. 11, n. 5, p. 238-242. 2006.

Submetido em setembro de 2014

Aprovado em novembro de 2014 